\title{
Assessment of Marital Dissatisfaction and Its Association with Sexual Dysfunction and Psychiatric Morbidities among Primary Health Attenders in Malaysia
}

Ahmad Faizal S MB Bch BAO ${ }^{\text {a }}$, Hatta Sidi MBBS, MMED(PSYCH) ${ }^{\text {a }}$, Suzaily Wahab MD, MMED(PSYCH) ${ }^{\text {a }}$, Leny Ss Drph $^{\mathrm{b}}$, Nora Mat Zin MD MMED(PSYCH) ${ }^{\mathrm{c}}$, Najwa Baharuddin Msc ${ }^{\mathrm{a}}$

${ }^{a}$ Department of Psychiatry, Universiti Kebangsaan Malaysia Medical Centre, Kuala Lumpur, 56000 Cheras Kuala Lumpur, Malaysia

${ }^{b}$ Faculty of Medicine, Universiti Teknologi MARA

'Kulliyah of Medicine, International Islamic University of Malaysia (IIUM), Bandar Indera Mahkota, Kuantan Malaysia

\begin{abstract}
Introduction: Marital satisfaction is vital to the wellbeing and functioning of the individual and family. Marital dissatisfaction can lead to detrimental effects on mental, physical and family health. The study aimed to determine the proportion of marital dissatisfaction in outpatient setting and its association with sexual functioning and psychiatric morbidity in Kuala Lumpur, Malaysia. Materials \& Methods: A crosssectional study was conducted in selected primary care using purposive sampling. Data collection was done using socio-demographic questionnaire and several validated Malay version of self-administered questionnaires. Marital satisfaction was measured by the Malay version of Golombok-Rust Inventory of Marital State (Mal-GRIMS). Results: The prevalence of marriage dissatisfaction in sample population was about $37.3 \%$ with almost equal prevalence in both, $36.5 \%$ (male) and $37.8 \%$ (female). Using a regression analysis, the significant factors that affect marital dissatisfaction were respondent's age group between 31 40 years old (Adjusted Odds Ratio, AOR. $=11.4$, 95\% Confidence Interval, $\mathrm{Cl} .=1.2-110.9$ ), spouse's salary of RM1000-RM2000 (lower income category) ( $A O R=7.3,95 \% \mathrm{Cl}=1.9-28.1$ ), anxiety case ( $A O R=4.8,95 \% \mathrm{Cl}=1.1$ 21.5), depression case $(A O R=4.8,95 \% \mathrm{Cl}=1.0-22.8)$, female sexual dysfunction in term of arousal function $(A O R=0.01,95 \% \mathrm{Cl}=0.0-0.7)$, satisfaction dysfunction $(A O R=9.4,95 \% \mathrm{Cl}=1.5-58)$ and pain function $(\mathrm{AOR}=43.7,95 \% \mathrm{Cl}=1.28$ - 1489.2). Conclusion: Marital dissatisfaction can be influenced by financial factor, sexual dysfunction and presence of psychiatric morbidity. Hence, in management of marital discord, thorough screening of these factors should be prioritized in clinical setting.
\end{abstract}

Keywords. Marital dissatisfaction, psychiatric morbidity, sexual dysfunction,

\section{INTRODUCTION}

Approximately more than $90 \%$ of the world population had been married at least once ${ }^{1}$. According to the report of recent population study in Malaysia in $2014^{1}$, about $61 \%$ of the population are married. Hence, research on the marriage is very important to provide the information and evidence for policy planning and provision of health service, since the quality of the marriage is among important determinant of healthy individual and family ${ }^{2}$.

Marital satisfaction can be defined as the degree of contentment regarding specific aspects of the marital relationship and the whole relationship

Corresponding author:

Professor Dr Hatta Sidi

Department of Psychiatry, Universiti Kebangsaan

Malaysia Medical Centre

Jalan Yaacob Latif, Bandar Tun razak

56000 Cheras, Kuala Lumpur, Malaysia

Email: hattasidi@hotmail.com

Tel : $+603-91456142$

Fax : +603-91737841 as well. It involves multiple factors including psychological, socioeconomic and spiritual component $^{3}$. It can also be described as an attitude of greater or lesser favourability toward an individual own marital relationship. Evidences from previous studies showed that marital functioning is consequential for health where the negative dimensions of marital functioning may have direct and indirect influences on outcomes of individual health through different mechanism and factors ${ }^{4}$. In other word, marital satisfaction is a vital component to population mental health. Reason being, mental health is people's compatibility with the world around, which leads to happiness and effective wellbeing. In view of marital satisfaction is one of the most important aspects of compatibility ${ }^{5}$, it was not wrong to assume that marital satisfaction was strongly related with mental health.

There are many factors that could influence marital satisfaction among married couples. Sexual functioning is one of the issues. It has a significant effect on the quality of life ${ }^{5,6}$. However, it could be either unreported or under-diagnosed. 
People with psychiatric co-morbidity and also suffered from sexual dysfunction (SD) were under diagnosed and went untreated because of the communication barriers between the patients and physicians ${ }^{6}$. Psychological distress and psychiatric morbidity had been shown to reduce the marital satisfaction in spouses of alcohol dependent patients ${ }^{6}$. The persistence of sexual problems has significant negative impact on patient's satisfaction and adherence with the treatment, quality of life and partnership. If sexual dysfunction is ignored, it may maintain the psychiatric disorder, and lead to non-adherence and subsequently compromise the treatment outcome ${ }^{7}$. Hence, routine assessment of sexual functioning may need to be integrated into ongoing care to identify and address problems early.

In Malaysia, recent National Health and Morbidity Survey had revealed that, the prevalence of mental health problems among adults showed an increasing trend; increased from $10.7 \%$ in 1996 to $29.2 \%$ in $2015^{8}$. This gave rise to the need for further research to look into factors that contribute to the increasing pattern of mental health problems in adult population. The main aim of this study was to determine the level of marital dissatisfaction and its association with SD and psychiatric morbidities among married couples.

\section{METHODOLOGY}

Study design

This was a cross sectional study done among 161 clinic attenders in primary healthcare clinic of a teaching hospital in a suburban area of Kuala Lumpur, Malaysia. It was conducted for a period of 6 months (January to July 2016).

\section{Sampling}

Purposive sampling method was conducted among the clinic attenders who fulfilled the inclusion criteria which were: individual aged 18 years old and above, married and able to understand Malay language. Individuals with psychiatric illness undergoing treatment, had physical disability or not consented to participate were excluded. Sample size was determined using Open Epi software based on a study by Robello ${ }^{9}$ which showed that the prevalence of marital dissatisfaction was about $14 \%$ giving the minimum sample of 185 respondents.

\section{Data collection}

Data collection was done using the questionnaire for demographic and marital profiles, as well as several validated self-administered questionnaires: Malay version of Golombok-Rust Inventory of Marital State (Mal-GRIMS), Malay version of International Index of Erectile Function (Mal-IIEF-15), Malay version of Female Sexual Function Index (MVFSFI), and Malay version of Hospital Anxiety \& Depression Scale (HADS).
Demographic and Marital Profile

This questionnaire was designed to obtain subject demographic and marital information which included age of both subject and spouse, educational background, employment status, medical history, incomes, duration of courtship and duration of marriage, living arrangement and type of marital union.

\section{Golombok-Rust Inventory of Marital State (GRIMS)}

The GRIMS is a 28-item questionnaire containing a series of 14 positively scored items and 14 negatively scored items regarding marital relationship. Each item is answered on a 4-point scale from "strongly agree", "agree", "disagree" and "strongly disagree" which ranges from 3 to 0 . A total score is then computed (range, 0-84), with a high score indicating a likelihood of marital dissatisfaction. The raw scores are then converted to standard scores (range, 1-9), with a cutoff point of 5 . A total transformed score of between 6 and 9 indicates a range of marital dissatisfaction from poor to very severe problems in the marriage. The reliability of the GRIMS is 0.91 for men and 0.87 for women, with validity being demonstrated under various situations ${ }^{10}$. The validated Malay version of GRIMS (Mal-GRIMS) was used in the present study ${ }^{11}$.

Malay version of the 15 -item International Index of Erectile Function (Mal-IIEF-15)

The Malay version of the IIEF comprises of 15 items that evaluates five distinct domains of the male sexual function. These domains and the corresponding IIEF items that tap into them are erectile function (EF, questions $1,2,3,4,5$, and 15), orgasmic function (OF, questions 9 and 10), sexual desire (SD, questions 11 and 12), intercourse satisfaction (ICS, questions 6,7 , and 8 ), and overall satisfaction (OS, questions 13 and 14$)^{12}$. Each item is rated on a Likert scale (0-5) and higher scoring indicates better sexual function. The Malay version of the IIEF is a reliable and validated instrument for sexual dysfunction measurement with Cronbach's al pha of 0.74 and intra-class correlation coefficient of $0.59^{12}$.

\section{MVFSFI (Malay version of Female Sexual Function} Index)

Malay version of Female Sexual Function Index (MVFSFI) was used to determine presence of sexual disorder. Female Sexual Function Index (FSFI) is a 19 -item questionnaire originally developed by Rosen ${ }^{13}$ which consisted of six domains of sexual function: desire, arousal, lubrication, orgasm, satisfaction and pain. MVFSFI was tested and found to be reliable and has good discriminant validity as for each domain as well as a whole, to be used among Malaysian community ${ }^{14}$. A total score of 55 was taken as the cutoff point to differentiate between female subject with SD and those without (sensitivity $=99 \%$, specificity $=97 \%$ ). The lower the scores, the higher will be the sexual dysfunction. The cutoff points for each domain were as follows: 
desire problems $\leq 5$ (sensitivity $=95 \%$, specificity $=$ $89 \%$ ), arousal difficulties $\leq 9$ (sensitivity $=77 \%$, specificity $=95 \%$ ), lubrication inadequacy $\leq 10$ (sensitivity $=79 \%, \quad$ specificity $=87 \%$ ), $\quad$ orgasmic difficulties $\leq 4$ (sensitivity $=83 \%$, specificity $=85 \%$ ), sexual dissatisfaction $\leq 11$ (sensitivity $=83 \%$, specificity $=85 \%$ ), and pain $\leq 7$ (sensitivity $=86 \%$, specificity= $95 \%)$.

HADS (Malay version of the Hospital Anxiety \& Depression Scale)

This is the validated Malay version ${ }^{15}$, which has depressive and anxiety subscales, each with 7 items. Each item is answered based on four point Likert scale (0-3), with possible scores ranged from 0 to 21 for each subscale. The score of 0 to 7 indicates normal range, score of 8 to 10 as suggestive or borderline and finally, a score of 11 or higher taken as positive screening for cases of anxiety or depression ${ }^{16}$.

Study Procedures

Prior to the study, approval to conduct the study was obtained from the Ethics Committee of the Universiti Kebangsaan Malaysia Medical Centre (UKMMC) (FF-2016-179) and from the administrative office of the participating clinics. The respondents who found to have depressive or anxiety disorder and sexual dysfunction would be referred for professional help.

Data analysis and measures of outcome

Data entry and analysis were done using SPSS version 23.0. The main outcome in this study was the marital satisfaction scores and proportion of marriage dissatisfaction among the study population. Meanwhile, associated factors include socio demographic profiles, marital profiles, sexual dysfunction scores or categories and psychiatric morbidities scores or categories. Appropriate statistical tests were used to determine the significant outcomes for the study variables.

Non parametric statistical test was done to identify association in not normally distributed data and logistic regression was used to determine the predictive factor for dependent variable which include Spearmann correlation. Dependent variable as dichotomous outcome was tested for association with the independent variables using simple and multiple logistic regressions. Normality of the data was explored using statistical test of KolmogrovSmirnov. The level of significant was determined at $a=0.05$.

\section{RESULT}

A total of 200 participants were approached; however about $16.5 \%$ refused to participate while six respondents did not returned their questionnaire with complete information. Among the reasons given for the refusal included feeling uncomfortable with the study questionnaires, as well as lack of interest and time to participate. Therefore total analysed sample was 161 . The median age of the respondents was 37 years old with majority of them were females (60.9\%), Malays (93.8\%) and with tertiary education level (62.1\%). Table I showed the sociodemographic profiles of the respondents.

Sociodemographic characteristics of respondents The median age of the respondents was 37 years old with majority of them were females $(60.9 \%)$, Malays (93.8\%) and with tertiary education level (62.1\%). The median score was calculated as the distribution was not normally distributed. Majority was in full time employment $(59.0 \%)$ with the low income category of $<$ RM1000 per month (24.2\%).

\section{Marital profile and marital dissatisfaction among the respondents}

The median marriage duration was 10 years and only minority was in arranged type of marriage $(11.2 \%)$. Majority of the respondents were married to the spouse in the age group of 31 to 40 years old, had tertiary level of education and with full time employment status.

\section{Psychiatric Morbidity scores of the respondents using HADS}

A minority of the respondents found to have anxiety (8.1\%) and depressive $(9.3 \%)$ symptoms.

\section{Sexual function scores of the respondents}

From 63 male respondents assessed, the prevalence of erectile dysfunction, orgasmic dysfunction, sexual desire dysfunction, intercourse dysfunction and overall dissatisfaction were $65.1 \%, 63.5 \%, 96.8 \%$, $81 \%$ and $54 \%$ respectively. (Table I)

Table I: Category of level of sexual dysfunction among the male respondents according to IIEF scores ( $n=63$ )

\begin{tabular}{|c|c|c|c|c|c|c|c|c|c|c|}
\hline \multirow[t]{2}{*}{$\begin{array}{l}\text { Severity of sexual } \\
\text { dysfunction category }(n=63)\end{array}$} & \multicolumn{2}{|c|}{$\begin{array}{l}\text { Domain } \\
\text { Erectile } \\
\text { Function }\end{array}$} & \multicolumn{2}{|c|}{$\begin{array}{l}\text { Orgasmic } \\
\text { function }\end{array}$} & \multicolumn{2}{|c|}{$\begin{array}{l}\text { Sexual } \\
\text { Desire }\end{array}$} & \multicolumn{2}{|c|}{$\begin{array}{l}\text { Intercourse } \\
\text { satisfaction }\end{array}$} & \multicolumn{2}{|c|}{$\begin{array}{l}\text { Overall } \\
\text { satisfaction }\end{array}$} \\
\hline & $\mathbf{N}$ & $\%$ & $\mathbf{N}$ & $\%$ & $\mathbf{N}$ & $\%$ & $\mathbf{N}$ & $\%$ & $\mathbf{N}$ & $\%$ \\
\hline Severe dysfunction & 8 & 12.7 & 9 & 14.3 & 2 & 3.2 & 10 & 15.9 & 5 & 7.9 \\
\hline Moderate dysfunction & 2 & 3.2 & 5 & 7.9 & 22 & 34.9 & 4 & 6.3 & 2 & 3.2 \\
\hline Mild to moderate dysfunction & 8 & 12.7 & 11 & 17.5 & 29 & 46.0 & 13 & 20.6 & 8 & 12.7 \\
\hline Mild dysfunction & 23 & 36.5 & 15 & 23.8 & 10 & 15.9 & 24 & 38.1 & 19 & 30.2 \\
\hline No dysfunction & 22 & 34.9 & 23 & 36.5 & 2 & 3.2 & 12 & 19.0 & 29 & 46.0 \\
\hline
\end{tabular}


It was also found that from the total FSFI score, about one-fifth of female respondents belongs to category of having FSD whom scored $\leq 55$ on MVFSFI, making the overall prevalence of FSD $20.4 \%$. According to the specific domains, the prevalence of women with desire problems, arousal difficulties, lubrication inadequacy, orgasmic dysfunction, sexual dissatisfaction and sexual pain were $26.5 \%, 20.4 \%$, $15.3 \%, 12.2 \%, 33.7 \%$ and $18.4 \%$ respectively.

(Table II)
Almost one-quarter of the respondents were in the poor marriage category score (23.0\%). Meanwhile, only $1.9 \%$ of the patients could be categorized as having very severe problems in their marriage. Other than that, using the GRIMS transformed scores, it was found that majority of the respondents have satisfactory marriage (62.7\%). Hence, the prevalence of marriage dissatisfaction in sample population was about $37.3 \%$ with almost equal prevalence in both, $36.5 \%$ (male) and $37.8 \%$ (female). (Table III)

Table II: Prevalence of female respondent with sexual dysfunction according to MVFSFI domain

\begin{tabular}{|c|c|c|c|c|c|c|c|c|c|c|c|c|}
\hline \multirow[t]{3}{*}{ Variable } & \multicolumn{12}{|c|}{ Domain } \\
\hline & \multicolumn{2}{|c|}{ Desire } & \multicolumn{2}{|c|}{ Arousal } & \multicolumn{2}{|c|}{ Lubrication } & \multicolumn{2}{|c|}{ Orgasm } & \multicolumn{2}{|c|}{ Satisfaction } & \multicolumn{2}{|c|}{ Pain } \\
\hline & $\mathrm{n}$ & $\%$ & $\mathrm{n}$ & $\%$ & $\mathbf{N}$ & $\%$ & $\mathrm{n}$ & $\%$ & $\mathrm{n}$ & $\%$ & $\mathrm{n}$ & $\%$ \\
\hline No dysfunction & 72 & 73.5 & 78 & 79.6 & 83 & 84.7 & 86 & 87.8 & 65 & 66.3 & 80 & 81.6 \\
\hline Dysfunction & 26 & 26.5 & 20 & 20.4 & 15 & 15.3 & 12 & 12.2 & 33 & 33.7 & 18 & 18.4 \\
\hline
\end{tabular}

Table III: Proportion of respondent with sexual functioning category according to marital satisfaction category

\begin{tabular}{|c|c|c|c|c|c|}
\hline \multicolumn{2}{|l|}{ Variable } & \multicolumn{4}{|c|}{ Marital satisfaction category } \\
\hline \multirow[t]{2}{*}{ Gender } & \multirow[t]{2}{*}{$\begin{array}{l}\text { Sexual functioning } \\
\text { domain }\end{array}$} & \multicolumn{2}{|c|}{$\begin{array}{l}\text { Non-problematic } \\
\text { marriage }\end{array}$} & \multicolumn{2}{|c|}{ Problematic marriage } \\
\hline & & $\mathbf{N}$ & $\%$ & $\mathbf{N}$ & $\%$ \\
\hline \multirow[t]{15}{*}{ Male } & Erectile function & & & & \\
\hline & No dysfunction & 16 & 72.7 & 6 & 27.3 \\
\hline & Yes Dysfunction & 24 & 58.5 & 17 & 41.5 \\
\hline & Orgasm & & & & \\
\hline & No dysfunction & 16 & 69.6 & 7 & 30.4 \\
\hline & Yes Dysfunction & 24 & 60.0 & 16 & 40.0 \\
\hline & Sexual desire & & & & \\
\hline & No dysfunction & 8 & 80.0 & 2 & 20.0 \\
\hline & Yes Dysfunction & 32 & 60.4 & 21 & 39.6 \\
\hline & Intercourse satisfaction & & & & \\
\hline & No dysfunction & 10 & 83.3 & 2 & 16.7 \\
\hline & Yes Dysfunction & 30 & 58.8 & 21 & 41.2 \\
\hline & Overall satisfaction & & & & \\
\hline & No dysfunction & 21 & 72.4 & 8 & 27.6 \\
\hline & Yes Dysfunction & 19 & 55.9 & 15 & 44.1 \\
\hline \multirow[t]{18}{*}{ Female } & Desire & & & & \\
\hline & No dysfunction & 1 & 100.0 & 0 & 0.0 \\
\hline & Yes Dysfunction & 60 & 61.9 & 37 & 38.1 \\
\hline & Arousal & & & & \\
\hline & No dysfunction & 0 & 0.0 & 0 & 0.0 \\
\hline & Yes Dysfunction & 61 & 62.2 & 37 & 37.8 \\
\hline & Lubrication & & & & \\
\hline & No dysfunction & 0 & 0.0 & 0 & 0.0 \\
\hline & Yes Dysfunction & 61 & 62.2 & 37 & 37.8 \\
\hline & Orgasm & & & & \\
\hline & No dysfunction & 46 & 73.0 & 17 & 27.0 \\
\hline & Yes Dysfunction & 15 & 42.9 & 20 & 57.1 \\
\hline & Satisfaction & & & & \\
\hline & No dysfunction & 0 & 0.0 & 0 & 0.0 \\
\hline & Yes Dysfunction & 61 & 62.2 & 37 & 37.8 \\
\hline & Pain & & & & \\
\hline & No dysfunction & 0 & 0.0 & 0 & 0.0 \\
\hline & Yes Dysfunction & 61 & 62.2 & 37 & 37.8 \\
\hline
\end{tabular}


Association between sociodemographic profiles with marital dissatisfaction category among the respondents

Marital satisfaction level category was analysed as dichotomous outcome using binary logistic regression. Analysis using simple logistic regression had found that several independent variables were the significant factors for the odds of having problematic marriage. Outcome reference group was having non-problematic marriage. The significant factors found were in categories of age groups of respondents and their spouse, spouse's salary, anxiety caseness, depression caseness, male sexual dysfunction domains and female sexual dysfuunction domains as shown in Table VI.

Further analysis using multiple logistic regressions (MLR) was conducted to adjust for confounders for all the significant variables in simple logistic regression models. The first MLR model for the whole study population were tested for sociodemographic, marital, clinical co-morbidities and psychiatric morbidities. Enter methods were used. Interaction and multi-collinearity were checked and not found. Hosmer-Lemeshow test, $(\mathrm{p}=0.862)$, classification table (overall correctly classified percentage $(73.3 \%$ ) were applied to check for model fitness. The model showed that after adjustment with other sociodemographic variables, respondents spouse age groups were not significantly associated with marital dissatisfaction. However, respondents' age group and spouse monthly salary did showed significant association. Respondents in the age group of 31 to 40 years old were 11 times more likely to have problematic marriage compared to one in the age group of 20-30 years old. Meanwhile, for spouse's salary, respondents whom their spouse salary was between RM1001 to RM2000 almost 7 times more likely to have problematic marriage compared to those with spouse salary of less than RM1000. Furthermore, respondents who have anxiety and depressive disorders were found to be almost 5 times more likely to be in problematic marriage compares to those not having these disorders.

The second MLR model was conducted for male respondents only includes all the significant independent variables. Enter methods were used. Interaction and multi-collinearity were checked and not found. Hosmer-Lemeshow test, $(p=0.852)$, classification table (overall correctly classified percentage $(79.4 \%)$ were applied to check for model fitness. The model showed that after adjustment with other significant variables none of the male sexual functioning domains were statistically significant.

The third model was then conducted for female respondents that also includes all significant variables in the simple logistic regression analysis.
Enter method were used. Interaction and multicollinearity were checked and not found. HosmerLemeshow test, $(p=0.479)$, classification table (overall correctly classified percentage $(84.7 \%)$ were applied to check for model fitness. The model showed that after adjustment with other significant variables, three variables in the female sexual functioning domain was found to be significant where respondent with satisfaction dysfunction was found to be almost 10 times more likely to be in problematic marriage and respondents with pain dysfunction have 43 times odds to be in problematic marriage compared to the one with no dysfunction. It was also revealed that female with arousal dysfunction have reduced odds to be in problematic marriage of about $1 \%$ compared to those without dysfunction. However, the desire dysfunction were found to be not a significant factor for marital satisfaction after all. (Table IV)

Relationship between psychiatric morbidities scores with marital dissatisfaction scores

There was a significant relationship found between anxiety category (chi square (df) $=13.78(2)$, $\mathrm{p}=0.001$ ) and depression category (chi square (df) $=12.20(2), p=0.002$ ) with the level of marital dissatisfaction. Additionally, there was fair, and positive significant correlation between HADS anxiety score $r_{s}=0.341 ; \quad p=<0.05$ and HADS depression score $r_{s}=0.430 ; \quad p=<0.01$ with transformed GRIMS score using Spearmann correlation.

Relationship between sexual function scores with marital satisfaction scores.

For male respondents, using Spearman correlation there was a negative weak but significant correlation between IIEF Sexual Desire domain score $r_{s}=-0.271, p<0.05$ with the GRIMS transformed scores. Meanwhile, for female respondents, there was a fair and negative correlation between MVFSFI Total score and GRIMS Transformed score, which was statistically significant $\mathrm{rs}(8)=-0.521, \quad \mathrm{p}=$ $<0.05$

\section{DISCUSSION}

Majority of respondents in this study were females and from Malay ethnicities. When compared to other studies done in local setting, study among Malaysian married couples in Peninsular Malaysia shared almost similar demographic profile where majority of them were females $(55.8 \%)$, Malay $(81.6 \%)$ and age around 40 years old ${ }^{18}$. Respondents with age group of 31-40 years old were found to more likely to have problematic marriage. The reason could be, person in this age group already achieved financial stability and were more into their career which means that this might provide them with the opportunity to meet new people and contemplating to find another partner in their life especially if they were married at a very young age. 
Table IV: Factors associated with category of marital dissatisfaction (using simple logistic regression and multiple logistic regression)

\begin{tabular}{|c|c|c|c|c|c|c|c|}
\hline Variable & Crude OR & (95\%Cl OR) & $\begin{array}{l}\mathrm{x}^{2} \\
\text { stat(df) }\end{array}$ & $\begin{array}{l}\mathrm{P} \\
\text { value }^{\mathrm{a}}\end{array}$ & $\begin{array}{l}\text { Adjusted } \\
\text { OR }\end{array}$ & (95\%Cl OR) & $P$ value \\
\hline \multicolumn{8}{|l|}{ Age group (years) } \\
\hline $20-30$ & 1.00 & & 15.12 & $0.007^{*}$ & 1.00 & & 0.084 \\
\hline $31-40$ & 6.00 & $(2.13,16.85)$ & $(3)^{\mathrm{b}}$ & $0.001^{*}$ & 11.40 & $(1.17,110.92)$ & $0.036^{*}$ \\
\hline $41-50$ & 4.94 & $(1.62,15.09)$ & & $0.005^{*}$ & 0.77 & $(0.01,49.17)$ & 0.901 \\
\hline $51-60$ & 4.00 & $(1.37,11.67)$ & & $0.011^{*}$ & 1.33 & $(0.03,64.90)$ & 0.886 \\
\hline \multicolumn{8}{|l|}{ Spouse age group (years) } \\
\hline $20-30$ & 1.00 & & 11.26 & $0.024^{*}$ & 1.00 & & 0.453 \\
\hline $31-40$ & 3.96 & $(1.49,10.55)$ & $(3)^{b}$ & $0.006^{*}$ & 5.45 & $(0.43,69.23)$ & 0.191 \\
\hline $41-50$ & 4.23 & $(1.35,13.25)$ & & $0.013^{*}$ & 2.15 & $(0.12,37.33)$ & 0.599 \\
\hline $51-60$ & 3.95 & $(1.44,10.87)$ & & $0.008^{*}$ & 6.15 & $(0.14,273.13)$ & 0.348 \\
\hline \multicolumn{8}{|l|}{$\begin{array}{l}\text { Spouse monthly salary (RM) } \\
<1000\end{array}$} \\
\hline $1001-2000$ & 1.00 & & 13.32 & & 1.00 & & $0.010^{*}$ \\
\hline $2001-3000$ & 3.04 & $(1.11,8.37)$ & $(5)^{\mathrm{b}}$ & $0.036^{*}$ & 7.34 & $(1.92,28.13)$ & $0.004^{*}$ \\
\hline $3001-4000$ & 1.87 & $(0.77,4.57)$ & & $0.031^{*}$ & 1.71 & $(0.61,4.79)$ & 0.308 \\
\hline $4001-5000$ & 0.68 & $(0.20,2.37)$ & & 0.167 & 0.72 & $(0.18,2.83)$ & 0.632 \\
\hline \multirow[t]{2}{*}{$>5000$} & 0.51 & $(0.13,2.01)$ & & 0.547 & 0.25 & $(0.05,1.41)$ & 0.116 \\
\hline & 0.31 & $(0.07,1.51)$ & & 0.337 & 0.37 & $(0.06,2.34)$ & 0.293 \\
\hline \multicolumn{8}{|l|}{$\begin{array}{l}\text { Psychiatric morbidities } \\
\text { Anxiety }\end{array}$} \\
\hline Non case & 1.00 & & & & 1.00 & & \\
\hline Case & 4.28 & $(1.25,14.58)$ & $5.95(1)$ & $0.020^{*}$ & 4.80 & $(1.08,21.48)$ & $0.043^{*}$ \\
\hline \multicolumn{8}{|l|}{ Depression } \\
\hline Non case & 1.00 & & & & 1.00 & & \\
\hline Case & 5.44 & $(1.65,17.98)$ & $8.92(1)$ & $0.005^{*}$ & 4.82 & $(1.02, \quad 22.83)$ & $0.042^{*}$ \\
\hline \multicolumn{8}{|l|}{ Sexual functioning } \\
\hline Male & & & & & 1.00 & & \\
\hline No EF dysfunction & 1.00 & & & & 1.66 & & \\
\hline Yes EF dysfunction & 1.89 & $(0.61,5.82)$ & $1.27(1)$ & $0.028^{*}$ & 1.00 & $(0.15,18.97)$ & 0.682 \\
\hline No OF dysfunction & 1.00 & & & & 0.80 & & 0.834 \\
\hline Yes OF dysfunction & 1.52 & $(0.51,4.53)$ & & & 1.00 & $(0.11,6.15)$ & 0.459 \\
\hline No SD dysfunction & 1.00 & & $0.58(1)$ & 0.449 & 3.00 & & 0.360 \\
\hline Yes SD dysfunction & 2.62 & $(0.50,13.59)$ & & & 1.00 & $(0.16,55.22)$ & 0.275 \\
\hline No ICS dysfunction & 1.00 & & $1.51(1)$ & 0.250 & 4.14 & & \\
\hline Yes ICS dysfunction & 3.50 & $(0.69,17.64)$ & & & 1.00 & $(0.20,86.78)$ & \\
\hline No OV dysfunction & 1.00 & & $2.77(1)$ & 0.129 & 2.66 & & 0.054 \\
\hline \multirow[t]{2}{*}{ Yes OV dysfunction } & 2.07 & $(0.72,5.98)$ & & & & $(0.46,15.43)$ & $0.034^{*}$ \\
\hline & & & $1.87(1)$ & 0.177 & 1.00 & & 0.109 \\
\hline Female $^{c}$ & & & & & 8.72 & & 0.391 \\
\hline No Desire dysfunction & 1.00 & & & & 1.00 & & $0.016^{*}$ \\
\hline Yes Desire dysfunction & 4.91 & $(1.88,12.80)$ & $11.38(1)$ & $0.001^{*}$ & 0.01 & $(0.97,78.62)$ & $0.036^{*}$ \\
\hline No Arousal dysfunction & 1.00 & & & & 1.00 & & \\
\hline Yes Arousal dysfunction & 2.44 & $(0.90,6.94)$ & $3.10(1)$ & 0.079 & 0.03 & $(0.00,0.73)$ & \\
\hline No Lubrication dysfunction & 1.00 & & & & 1.00 & & \\
\hline Yes Lubrication dysfunction & 2.95 & $(0.95,9.11)$ & $3.61(1)$ & 0.061 & 6.85 & $(0.00,2.25)$ & \\
\hline No Orgasm dysfunction & 1.00 & & & & 1.00 & & \\
\hline Yes Orgasm dysfunction & 2.61 & $(0.76,8.94)$ & $2.38(1)$ & 0.126 & 9.40 & $(0.09,554.93)$ & \\
\hline No Satisfaction dysfunction & 1.00 & & & & 1.00 & & \\
\hline Yes Satisfaction dysfunction & 2.61 & $(0.76,8.94)$ & $2.38(1)$ & 0.126 & 43.65 & $(1.52,58.04)$ & \\
\hline No Pain dysfunction & 1.00 & & & & & & \\
\hline Yes Pain dysfunction & 3.26 & $(1.13,9.39)$ & $4.97(1)$ & $0.028^{*}$ & & $\begin{array}{l}(1.28 \\
1489.17)\end{array}$ & \\
\hline
\end{tabular}

DEPENDENT VARIABLE: MARITAL SATISFACTION CATEGORY

${ }^{a}$ Likelihood ratio ${ }^{b}$ Wald test, ${ }^{c}$ separate LR model used for different gender

${ }^{*} \mathrm{p}<0.05$ taken as level of significant, $\mathrm{OR}=$ Odd Ratio, $\mathrm{x}^{2}=$ chi square 
This study revealed that monetary factor in the marriage whom the spouse's monthly income was low and associated with marital dissatisfaction. These findings supported the evidence from the previous study done in 2012, which found that financial issues were a stronger predictors of divorce compared to other marital disagreement and money dispute between the couples would correlate with lower marital satisfaction ${ }^{19}$. Interestingly, if the spouse monthly income was between RM1000 to RM2000 it became a protective factor for marriage dissatisfaction when compared to be spousal with income of less than RM1000. The findings might imply a financial factor plays an important role in marital satisfaction. However, spousal income might also contribute to the conflict in terms of superiority in the family. Respondents might resent the spouse who earned more than them, which explained the reason of higher spouse salary would contribute to higher chances to be in problematic marriage.

Findings from the study revealed that the prevalence of sexual dysfunction domains among the male respondents, involved more than half of them with the highest prevalence of sexual desire disorder of $96.8 \%$. This figure does compliment the findings of another study which showed that the prevalence of male sexual dysfunction varied in Asia ${ }^{20}$, which figures ranged between $9 \%$ to $73 \%$. Furthermore, the sexual desire dysfunction is associated with higher marital satisfaction.

While for female respondents, the overall prevalence of FSD was $20.4 \%$. This finding gave nearly similar prevalence from study done in year 2010 using similar instruments among female patients with diabetes in Selangor where patients with sexual dysfunction was only about $18.2 \%^{21}$. Moreover, it it was found that for the females, the sexual function scores showed negative correlation with the GRIMS scores. Surprisingly, the sexual dysfunction in arousal domain predicted better marital satisfaction, this might indicate that female respondents did not consider arousal as importance for marital satisfaction. Nevertheless, satisfaction and pain function significantly predicts odds of marital problems if they were present.

Other than that, it was found that less than one-fifth of the respondent have psychiatric morbidities for both anxiety and depression categories. From this, it was found that both of these psychiatric morbidities were significantly associated with category of marital dissatisfaction both as category and scores. It was observed that when the psychiatric morbidities scores increased, the GRIMS scores also increased. Moreover, respondent who have cases of anxiety and depression were found to be four times more likely to be in problematic marriage. This findings supported the past evidence of marital dissatisfaction was associated with the presence of any disorder, any mood disorder, any anxiety disorder, and any substance-use disorder ${ }^{22}$.
This current study findings did have few limitation. Firstly, like other cross sectional study it might not be able to explain the causability. The population distribution in term of gender and ethnicity also could hampers the generalizability of the findings. In this study the reason could be contribute by the reason that sexuality and marital dissatisfaction have always been somekind of taboo and might not be perceived as not appropriate to be talk about with strangers and moreso if the researcher were different in gender and ethnicities. However, this study was still useful because it managed to capture the information to achive its objective. Future study should consider the aspect of gender and ethnicity when recruiting the interviewer for this type of study subject. Other than that, random sampling method would improve this study finding if logistic limitation such as limited study period and more funding could be obtained.

Furthermore, findings from this study had provided added knowledge in psychiatry field where sexuality was scarcely studied especially so in the country with majority of the population are Muslims. Other than that, there were yet no concensus in the psychiatry field on the gold standard tool to measure the marital dissatisfaction among married couples because for example besides GRIMS, researchers was found to also used ENRICH questionnaire to measure the same thing. Therefore, longitudinal and larger sample size study comparing the tools would be invaluable and would make comparison easier and lead to better decision in patient diagnosis and treatment on marital dissatisfaction. Perhaps, these instruments could be recommended as routine screening tools for married couples in the future.

\section{CONCLUSION}

Sexual dysfunction and psychiatric morbidities plays an important role in the marital dissatisfaction among married couples. These findings should be considered when diagnosing and creating effective psychiatric intervention in future.

\section{A Conflict of interest:}

The authors have no conflicts of interests to declare.

\section{REFERENCES}

1. Lembaga Penduduk Dan Pembangunan Keluarga Negara. Laporan penemuan utama kajian penduduk dan keluarga kelima (KPKM-5). Kuala Lumpur: Bahagian Kependudukan LPPKN;2014

2. Greeff P, Tanya De Bruyne A. Conflict management style and marital satisfaction. Journal of Sex \&Marital Therapy 2000;26:321334.

3. Ziaee T, Jannati Y, Mobasheri E, Taghavi T, Abdollahi $\mathrm{H}$, Modanloo $\mathrm{M}$ et al. The relationship between marital and sexual satisfaction among married women employees at Golestan 
University of Medical Sciences, Iran. Iranian journal of psychiatry and behavioral sciences 2014;8:44.

4. Kiecolt-Glaser JK, Newton TL. Marriage and health: his and hers. Psychological bulletin 2001;127:472.

5. Kalhor M, Olyaie, N. Relationship between Marital Satisfaction and Mental Health of Married Women Referring to Health Centers in Sanandaj, Iran in 2014. Global Journal of Health Science 2016;9:19.

6. Kishor M, Pandit LV, Raguram R. Psychiatric morbidity and marital satisfaction among spouses of men with alcohol dependence. Indian journal of psychiatry 2013;55:360.

7. Bossini L, Fortini V, Casolaro I, Caterini C, Koukouna D, Cecchini F et al. [Sexual dysfunctions, psychiatric diseases and quality of life: a review]. Psychiatria Polska 2013;48:715-726.

8. Institute for Public Health. National Health and Morbidity Survey 2015: Volume II: NonCommunicable Diseases and Other Health Problems. Kuala Lumpur: Ministry of Health Malaysia;2016.

9. Rebello K, Junior MDS, Brito RCS. Fundamental factors in marital satisfaction: An assessment of Brazilian couples. Psychology 2014;5:777.

10. Rust J, Golombok S, Collier J. Marital problems and sexual dysfunction: How are they related? The British Journal of Psychiatry 1988;152:629631.

11. Quek KF, Low WY, Razack AH, Chua CB, Loh CS. The feasibility of the Golombok-Rust Inventory of Marital State (GRIMS) in assessing marital satisfaction in a Malaysian population. Journal of Sex \&Marital Therapy 2002;28:423426.

12. Quek KF, Low WY, Razack AH, Chua CB, Loh CS. Reliability and validity of the Malay version of the International Index of Erectile Function (IIEF-15) in the Malaysian population. International journal of impotence research 2002; 14:310-315.

13. Rosen C, Brown J, Heiman S, Leiblum C Meston $R$, Shabsigh $D$ et al. The Female Sexual Function Index (FSFI): a multidimensional selfreport instrument for the assessment of female sexual function. Journal of Sex \&Marital Therapy 2000;26:191-208.

14. Sidi H, Abdullah N, Puteh SEW, Midin M. The female sexual function index (FSFI): Validation of the Malay version. The journal of sexual medicine 2007;4:1642-1654.

15. Yusoff N, Low WY, Yip CH. Psychometric properties of the Malay Version of the hospital anxiety and depression scale: a study of husbands of breast cancer patients in Kuala Lumpur, Malaysia. Asian Pac J Cancer Prev 2011;12:915-7.

16. Snaith RP.The hospital anxiety and depression scale. Health and quality of life outcomes 2003;1:1.
17. Bruce N, Pope D, Stanistreet D. Quantitative methods for health research: a practical interactive guide to epidemiology and statistics: John Wiley \& Sons; 2008

18. Ismail R, Azlan HAN, Yusoff F. Assessing the relationship between quality of life and marital satisfaction among Malaysian married couples. Journal of Social Sciences and Humanities 2015; Special Issue 2:65-71.

19. Dew J, Britt S, Huston S. Examining the relationship between financial issues and divorce. Family Relations 2012;61:615-628.

20. Ho CC, Singam P, Hong GE, Zainuddin ZM. Male sexual dysfunction in Asia. Asian J Androl 2011;13:537-4.

21. Whisman MA. Marital dissatisfaction and psychiatric disorders: results from the National Comorbidity Survey. Journal of abnormal psychology 1999; 108:701.

22. Kamaralzaman S, Sidi H, Yau M, Budin SB, Sani A, Mohamed J. Sexual function of Malay women with type 2 diabetes mellitus: a preliminary study. ASEAN J Psychiatry 2010;11:1-8.

23. Sidi $\mathrm{H}$, Puteh SEW, Abdullah N, Midin $M$. Original Research-Epidemiology: The Prevalence Of Sexual Dysfunction And Potential Risk Factors That May Impair Sexual Function in Malaysian Women. The journal of sexual medicine 2007;4:311-321. 